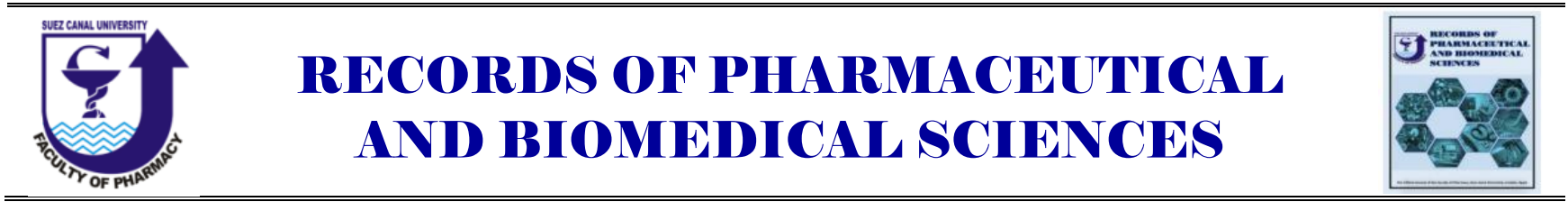

\title{
The Role of Novel Genes in Rheumatoid Arthritis Pathogenesis
}

\author{
Shaimaa A. Fattah ${ }^{a^{*}}$, Maha A. Abdel Fattah ${ }^{b}$, Eman T. Mehanna ${ }^{a}$, Noha M. Mesbaha, \\ Samy M. Saleh ${ }^{\mathrm{a}}$, Dina M. Abo-elmatty ${ }^{\mathrm{a}}$ \\ ${ }^{a}$ Department of Biochemistry, Faculty of Pharmacy, Suez Canal University, Ismailia, Egypt, ${ }^{b}$ Department of \\ Physical Medicine, Rheumatology and Rehabilitation, Faculty of Medicine, Suez Canal University, Ismailia, \\ Egypt
}

Received on: 27. 08. 2020

Revised on: 23. 10. 2020

Accepted on: 28. 10. 2020

*Correspondence Author:

Tel: +201202468251

E-mail address:

shimaa_abdaziz@pharm.suez.edu.eg

\begin{abstract}
Rheumatoid arthritis (RA) is a debilitating disease characterized by chronic symmetric polyarthritis involving peripheral small joints. Heterogeneity in RA pathophysiology extends to a molecular level. Understanding the complicated interaction between genetics, environment, and autoimmunity, and their function in pathogenesis, is necessary for getting further insight into the mechanisms and outcomes that manage disease development and progression. Pharmacogenomics emphasizes the relations of numerous genetic signatures with responses to traditional disease-modifying drugs and biologics. More than 100 genetic susceptibility loci have been recognized for RA through studies directed on patients with longstanding RA compared with healthy controls. So the interaction between genes and the environment may determine who is more susceptible to develop RA. This review pays attention to some recently discovered genetic risk loci in RA; ZNF804a, CDK1, YWHAH 14-3-3 $\eta$, and IL-17A. Also, their involvement in the etiology, pathogenesis, and outcome of the disease is explained, aiming to provide new insights into the pathogenesis of RA and the possibility to develop novel therapeutic approaches through targeting these genes.
\end{abstract}

Keywords: Rheumatoid arthritis; ZNF804a; CDK1; 14-3-3 $\eta$; YWHAH; IL-17A.

\section{Introduction}

Rheumatoid arthritis (RA) is an inflammatory rheumatic disease that induces prolonged synovial inflammation, ultimately generates disabling joint injury as well as systemic complications (Smolen and Steiner, 2003). Several epidemiologic types of research show that the prevalence of RA is $0.5 \%-$ $1.0 \%$ (Cribbs et al., 2015). $70 \%$ and $80 \%$ of RA patients possess autoantibodies such as rheumatoid factor (RF) and anti-citrullinated protein antibodies (ACPA) (Smolen and Steiner, 2003).
The RA pathological process represents an autoimmune inflammation of the synovial joint membrane with proliferation of synovial cells and the formation of pannus. This pannus granulation tissue causes bone deterioration and articular cartilage erosion. Synovial tissue dysfunction facilitates the penetration of macrophages, fibroblasts, and lymphatic cells inside it. Proinflammatory cytokines; mainly tumor necrosis factor (TNF), interleukin (IL) superfamilies, and growth factors; are produced by T-lymphocytes (Nemtsova et al., 2019). 
B-lymphocytes are involved in RF and ACPA autoantibodies production. Variances in ACPA and $\mathrm{RF}$ expression, disease manifestation rate and therapeutic response variability cause heterogeneity of RA patients that indicate the involvement of different pathophysiological mechanisms in the progression and development of the disease.

Most rheumatic diseases involve complicated features in which various genetic and environmental factors associate. Twin studies have concluded that the heritability of RA is $\sim 60 \%$ (MacGregor et al., 2000). These results refer principally to RA patients with positive ACPA, whereas the heritability of RA patients with negative ACPA seems to be lower. Since 2007, genome-wide association study (GWAS) technologies have aided the description of genetic risk factors for numerous miscellaneous disorders (Consortium, 2007). More than one hundred genetic loci have been linked to RA (Okada et al., 2014).

Figure 1 illustrates the complicated interaction between the "Bermuda triangle" of genetics, environment, and autoimmunity in RA pathogenesis. Environmental factors as smoking, bacteria, and viruses, cause epithelial damage which leads to an inflammatory response that activates cytokines, chemokines, and growth factors as tumor necrosis factor-alpha (TNF- $\alpha$ ), vascular endothelial growth factor (VEGF), and interleukins (ILs). These contribute to differentiation and proliferation of fibroblasts, increased synthesis, and activity of matrix metalloproteinases (MMP) that cause cartilage damage. Both genetic and environmental risk factors are associated with increased citrullination of proteins which lead to the production of ACPAs antibodies and allow an autoimmune response which also activates cytokines, chemokines, and growth factors causing inflammation of the synovial membrane of joints with synovial cells proliferation and pannus formation.

As a genetic factor is obviously implicated in RA, it is necessary to understand the recently associated genes and their pivotal roles in RA. This review will describe recent genes associated with RA, envisaging a more reliable understanding of RA pathogenesis.

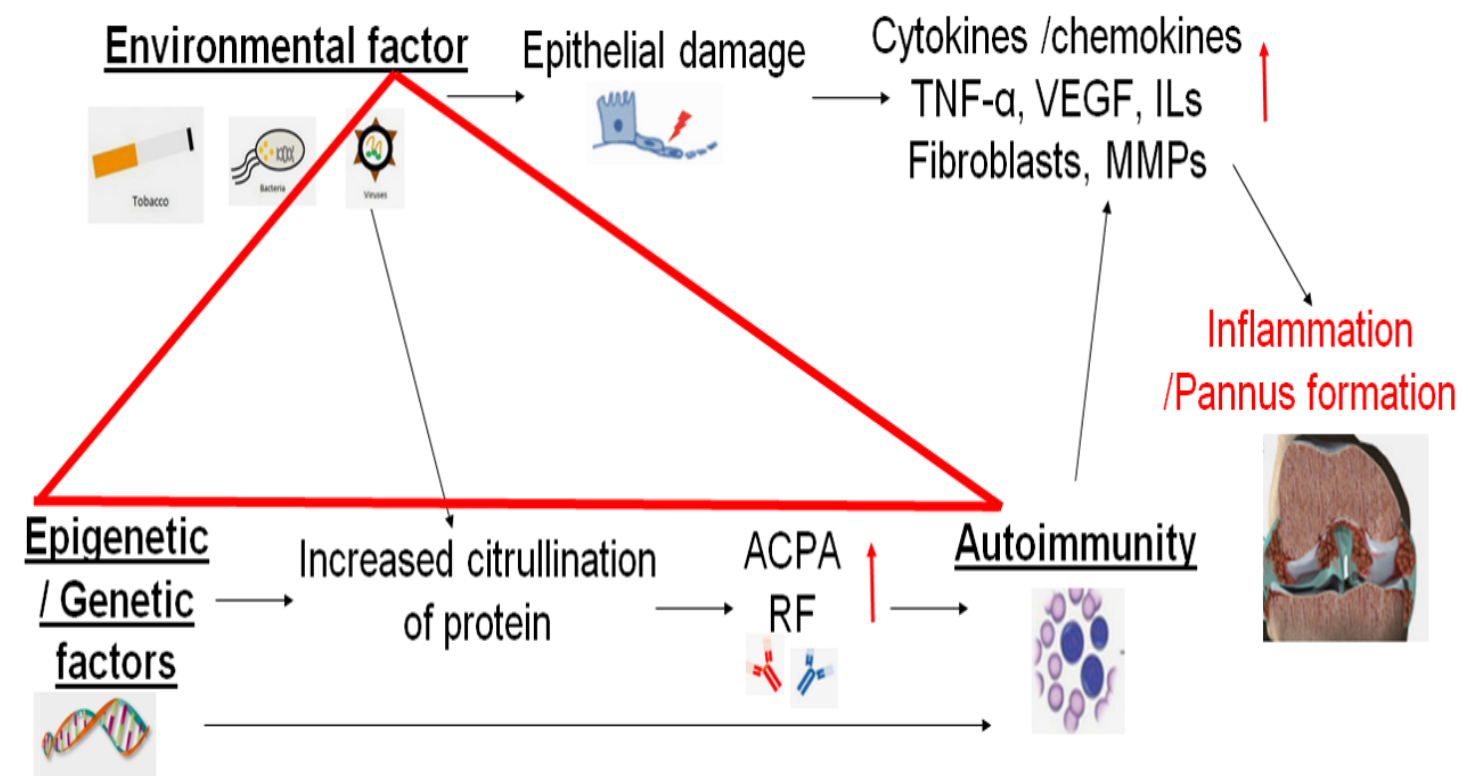

Figure 1. Bermuda triangle of rheumatoid arthritis: genetics, environment, and autoimmunity. TNF- $\alpha$ tumor necrosis factor-alpha. VEGF vascular endothelial growth factor. ILs interleukins, MMPs matrix metalloproteinases, ACPA anti-citrullinated protein antibodies, RF rheumatoid factor. 


\section{ZNF804a gene}

Zinc-finger proteins (ZNFs) are abundant protein aggregations that have a broad molecular variety. As ZNFs have deeply divided domains, they can combine with DNA, RNA, poly-ADP ribose (PAR) and other proteins (Gibson et al., 1988; Vrana et al., 1988). ZNFs are also associated with the organization of multiple cellular processes. ZNFs functions include transcriptional control, cell migration, actin targeting, DNA repair, signal transduction, ubiquitin-mediated protein degradation, and many other approaches (Linke et al., 2008).

Four exons and three introns on human chromosome 2q32.1 are found in ZNF804a gene which encodes a ZNF804a protein of 1210 amino acids (137 kDa) (Walters et al., 2010). While ZNF804a 's molecular function remains unknown, the sequence of amino acids contains the $\mathrm{C} 2 \mathrm{H} 2$ zinc-finger domain, indicating that ZNF804a plays a role in binding and transcribing DNA (Girgenti et al., 2012).

ZNF804a gene has been associated with bipolar disorder (BD) and schizophrenia (SZ) (Rao et al., 2017). ZNF804a is also distinguished as an important gene for anxiety disorder (Talkowski et al., 2012; Blake et al., 2014), autism spectrum disorder (Griswold et al., 2012), developmental disabilities and psychosis (Steinberg et al., 2011). In addition to the correlation of this gene with central nervous system diseases, it was recently identified as a systemic lupus erythematosus (SLE) vulnerability factor (Almlof et al., 2017).

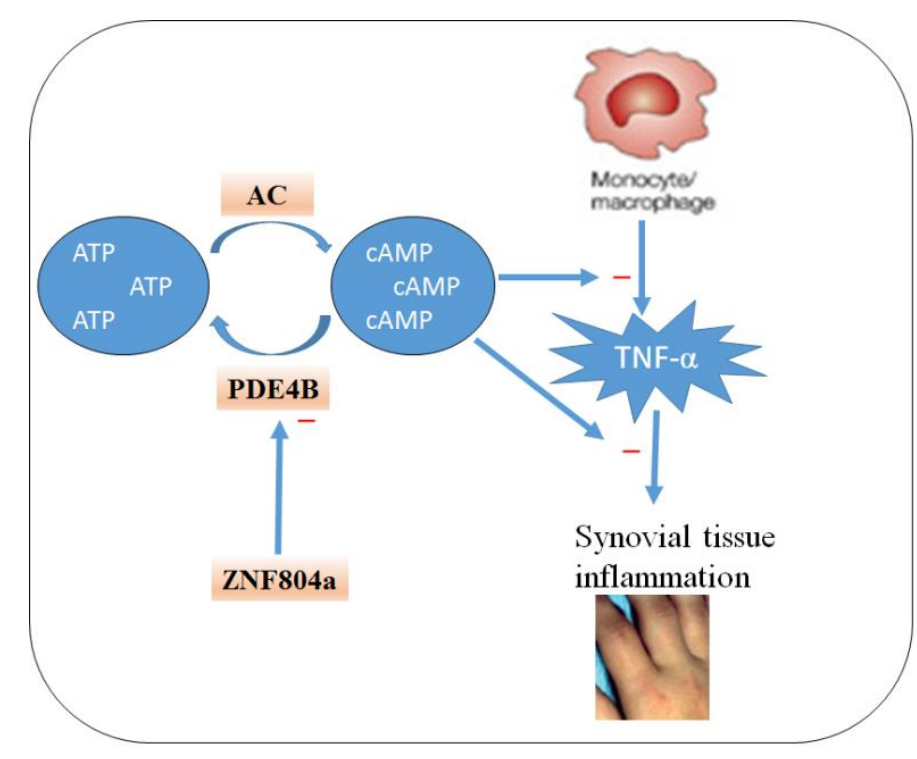

There is a well-known link between the ZNF804a gene and RA pathogenesis, where phosphodiesterase 4B (PDE4B) protein that is involved in inflammatory processes is downregulated by this gene (Girgenti et al., 2012). PDE4B suppression can increase the cyclic AMP (cAMP) intracellular level and thus maintain immune balance and alter inflammatory actions (Maurice et al., 2014). One efficient therapy for $\mathrm{RA}$ is PDE4B antagonists that reduce TNF- $\alpha$ secretion (Li et al., 2018). The ZNF804a gene can therefore decrease TNF- $\alpha$ in RA by decreasing PDE4B proteins (Figure 2). In a recent study, we established the correlation between ZNF804a expression and RA activity and severity. Our study reported the down-regulation of ZNF804a in RA patients. Expression of ZNF804a was negatively associated with serum TNF- $\alpha$ levels in the RA patients. ZNF804a gene downregulation is expected to raise the levels of TNF- $\alpha$ that is considered an essential cytokine involved in the pathogenesis of RA (Fattah et al., 2020).

Higher serum levels of TNF- $\alpha$ enhance RA disease activity, and severity as it is positively associated with levels of c-reactive protein (CRP), erythrocyte sedimentation rate (ESR), disease activity score (DAS)-CRP, DAS-ESR, RF, and ACPA (Wei et al., 2015) In our above-mentioned work; RA patients with lower expression of ZNF804a had considerably higher serum levels of CRP, DAS$\mathrm{CRP}$, and RF, suggesting an impact of ZNF804a expression on the disease activity and severity(Fattah et al., 2020).
Figure 2. The relation of ZNF804a and RA pathogenesis. ATP adenosine triphosphate, cAMP cyclic adenosine monophosphate, AC adenylate cyclase, PDE4B phosphodiesterase $4 \mathrm{~B}, \mathrm{ZNF} 804 \mathrm{a}$ zinc finger $804 \mathrm{a}, \mathrm{TNF}-\alpha$ tumor necrosis factor-alpha. - Indicates an inhibition (Fattah et al., 2020). 


\section{CDK1 gene}

Cyclin-dependent kinases (CDKs) control the phases of cell division, commencing with quiescence, the G1/S phase transition, DNA replication in $\mathrm{S}$ phase, nuclear breakdown, chromosome condensation, segregation, and cytokinesis (Crosby, 2007). CDK1, the first CDK identified in all species (Nurse and Thuriaux, 1980; Lohka et al., 1988), is retained and performs essential functions throughout mitosis. The $\mathrm{S}$ phase is triggered by CDK1 (Aleem et al., 2005).

CDK1 gene forms 9 exons on human chromosome 10q21.2, encoded as CDK1 enzyme (https://www.ncbi.nlm.nih.gov/gene? Db=gene\&Cm $\mathrm{d}=$ DetailsSearch\&Term=983). The development of fibroblasts in the synovium is correlated with CDK1 to generate a hyperplastic RA pannus (Sekine et al., 2008). Also, CDK1 activates the interferon (IFN) type I-induced phosphorylation of signal transducer and transcription 1 (STAT1) and enhances the upregulation of interferon-stimulated genes which leads to improvement of IFN-1 signaling (Wu et al., 2016), that is involved in RA pathogenesis (Gordon et al., 2012). IFN-1 cytokines were found in RA synovium (Hu et al., 2008). IFN-1 was also observed in SLE patient's sera (Petri, 2006).

The CDK1 gene is overexpressed in SLE (Wu et al., 2016; Almlof et al., 2017). We reported CDK1 gene overexpression in RA patients. The serum levels of IFN-1 were significantly higher in RA patients (Fattah et al., 2020).
There was an association between CDK1 overexpression and abnormal amplification of IFN-1 signaling in SLE (Wu et al., 2016). A significant positive correlation between CDK1 expression and IFN-1 serum levels was observed in our study. Consequently, CDK1 gene overexpression may contribute to an increase in the IFN-1 serum levels in RA patients, which is essential for RA pathogenesis (Figure 3). CDK1 expression was positively correlated with ACPA in RA patients while CRP, ESR, DAS-ESR, DAS$\mathrm{CRP}$ and RF had no association. This suggests that the CDK1 gene may impact the RA disease severity but not the activity (Fattah et al., 2020).

\section{YWHAH 14-3-3 Eta gene}

There are seven isoforms: $\alpha / \beta, \gamma, \delta / \zeta, \varepsilon, \eta, \theta / \tau$ and $\sigma$, in the 14-3-3 regulatory proteins (Maksymowych et al., 2014). Generally, these proteins are ubiquitous intracellular adapters (or chaperones) that interact with more than 200 intracellular proteins and regulate their activities (Kilani et al., 2007).

Serum 14-3-3 $\eta$, first described in 2007, is noticeable at a significantly higher serum and synovial fluid levels in RA patients than healthy people and those with other autoimmune diseases and viral/bacterial infections (Kilani et al., 2007). Extracellular 14-3-3 $\eta$ in RA patient serum is an indicator for cell damage that extremely stimulates pro-inflammatory cytokines and bone-degrading enzymes (Maksymowych and Marotta, 2014).

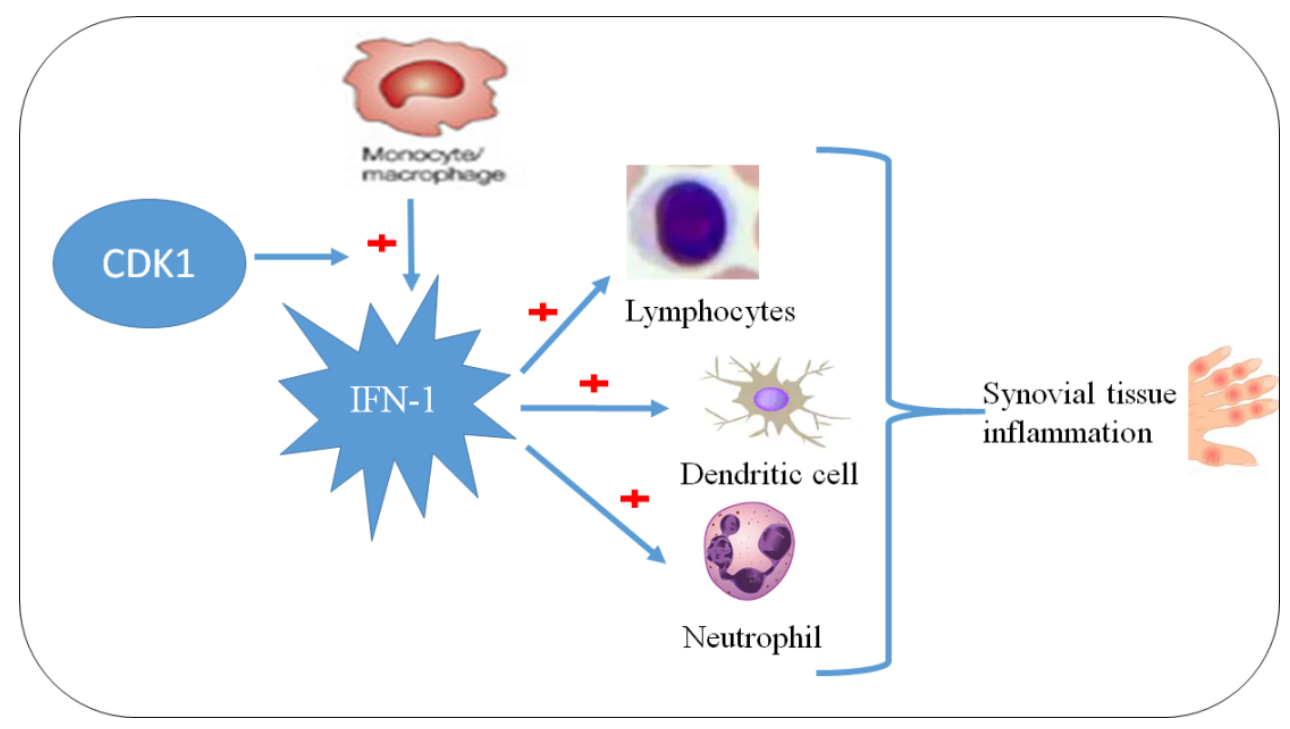

Figure 3. The relation of CDK1 and RA pathogenesis. CDK1 cyclin-dependent kinase 1, IFN interferon. + indicates stimulation. 
14-3-3 $\eta$ expression was strongly correlated with MMPs. ZMMPs are serine proteases, which play a significant role in tissue homeostasis. In the condition of RA, the discrepancy between these proteolytic enzymes expression and their cognate antagonist's triggers cartilage disintegration (Siebuhr et al., 2013). It has been defined that MMP expression is controlled by transcription factor Activator Protein 1 (AP-1) that determines intracellular signals, including Mitogen-Activated Protein Kinase (MAPK) (Kook et al., 2011). The extracellular regulated kinase (ERK), p38MAPK and Jun N-terminal kinase/stress-activated protein kinases JNK/SAPK, have been widely noticed in RA (Kyttaris, 2012).

In early RA patients with gradual joint destructions, de Launay et al. (2012) reported significant changes in ERK and JNK activation, but not in P38MAPK activation, stressing their potential importance to RA etiology.

Cell stimulation experiments have shown 14-3-3 $\eta$ stimulation of the innate immune system, leading to the activation of major signals such as MAPK/ ERK, SAPK/JNK, and the JAK-STAT pathway which regulates the inflammatory and degradative factors production (Maksymowych et al., 2014a). Various RA associated transcriptional factors such as receptor activator of nuclear factor Kappa-B ligand (RANKL), joint degradation factors such as MMP-9, and pro-inflammatory cytokines, IL-1 $\beta$, IL-6, TNF- $\alpha$ are upregulated by 14-3-3 $\eta$ (Maksymowych et al., 2014b). CRP and fibrinogen synthesis can be triggered in the liver by IL-6 (Rhodes et al., 2010).

YWHAH gene spans $10 \mathrm{~kb}$ and encodes a protein 246 amino acids long (Muratake et al., 1996). It consists of a long $8 \mathrm{~kb}$ intron and two $741 \mathrm{~kb}$ exons and is located on human chromosome 22q12.1q13.1 (Muratake et al., 1996; Takahashi, 2003). It codes the $\eta$ of the 14-3-3 family of proteins, which are primarily found in the brain (Grover et al., 2009). This gene has been associated with $S Z$ and psychotic BD (Wang et al., 2005; Grover et al., 2009). The YWHAH gene is expressed in synovial tissue (Kilani et al., 2007). YWHAH gene has been studied as a susceptibility gene for RA due to its action in joint deterioration. YWHAH 14-3-3 $\eta$ was upregulated by 4.7 fold in synovial fluid from RA patients (Balakrishnan et al., 2014). YWHAH was reported to be overexpressed by 3.27 fold in synovial membrane and by 2.37 fold in peripheral blood cells from psoriatic arthritis patients (Dolcino et al., 2015).

\section{IL-17A gene}

Interleukin (IL)-17A is a cytokine that is involved in many autoimmune and inflammatory disorders (Miossec and Kolls, 2012). It is produced by Th17 cells as well by cytotoxic CD8 $+\mathrm{T}$ cells $(\mathrm{Tc} 17$ cells), invariant natural killer T cells (iNKT cells), lymphoid tissue inducer cells (LTi cells), $\gamma \delta \mathrm{T}$ cells, and other hematopoietic and nonhematopoietic cells (Kim and Jordan, 2013). Experiments in vitro and in vivo have recognized the function of IL-17 in several cell types, which illustrate its relationship with the early and late chronic phases of many disorders. In keratinocytes, for example, IL-17A induces several chemokines expression, contributing to the mobilization of immune cells which characterize psoriasis (Beringer et al., 2016). Also, IL17A works locally on synoviocytes and osteoblasts leading to synovitis or joint damage in RA (Hot and Miossec, 2011; Ndongo-thiam and Miossec, 2015), which is one of the most severe chronic inflammatory diseases (Smolen et al., 2016).

The immunostaining of RA patients' synovial tissues has demonstrated that an IL-17 group of CD4+CD45RO+ T-memory cells has not been observed in synovial tissue from osteoarthritis (OA) patients. In comparison, the synovial fluid content of IL-17 is greater in RA patients than in OA, trauma and gout patients (Kotake et al., 1999). In the lymphocytic infiltrate and the hyperplasic lining of the RA synovium, the IL17A-producer cells are detected (Kotake et al., 1999). Th17 cells and synoviocytes interactions are critical, as they generate IL-17 massively (Noack et al., 2016).

IL-17A partly contributes to cartilage injury. Sample synovial RA studies show that the production of leukemia inhibitory factor (LIF), macrophage inflammatory protein (MIP)$3 \alpha /$ chemokine (C-C motif) ligand-20, and IL- 6 by RA synovium are triggered by IL-17A (Chabaud et al., 1998; Chabaud et al., 1999; Chabaud et al., 2000). Additionally, the discovery of RA synovium anti-IL-17 antibody considerably impaired the development of MMP-1, collagenases but not of MMP (Timp)-1 tissue inhibitors, indicating the clear interaction with mutual degradation of IL-17 (Chabaud et al., 2000). 
Several cytokines and chemokines, especially IL-6 and IL-8, are massively produced by synoviocytes which are activated by IL-17A and IL-17F (Zrioual et al., 2008; Hot and Miossec, 2011; Hot et al., 2011). Also, IL-17 is responsible for inducing tissue destruction through migration of synoviocyte and fostering a tissue- invasive phenotype (Hot et al., 2012; Bottini and Firestein, 2013; Li et al., 2013). The injury to the tissue involves degradation of the cartilage matrix and bone deterioration. The major source of matrix disruption is MMP. Amongst such, MMP-1, 2, 9, and 13 synoviocytes and chondrocytes are caused by IL-17 in RA (Chabaud et al., 2000).

IL-17A gene, which is located on chromosome locus 6p12, encodes the IL-17A cytokine (Jakubiuk-Tomaszuk et al., 2015). The IL17A gene occupies a total of 4252 bp composed of three exons and two introns and encodes a protein of 155 amino acids (http://atlasgeneticsoncology.org/Genes/GC_IL17A. html). The retinoid-related orphan receptor (ROR) $\gamma$ $\mathrm{T}$ and ROR $\alpha$ transcription factors regulate IL-17A expression. ROR $\gamma \mathrm{T}$ is expressed primarily by Th17 cells and drives their differentiation (Khan and Ansar Ahmed, 2015). The expression of IL-17A gene and growth of Th17 cells are surprisingly guided not just by microorganisms and tumors, but also by several environmental factors including nutrients, metabolites, hypoxia, toxins, $\mathrm{NaCl}$, and circadian rhythm (Kleinewietfeld et al., 2013). IL17 expression is increased in number of pathological disorders as asthma, pneumonitis and pulmonary fibrosis (Gurczynski and Moore, 2018). Also, the IL17A gene has been upregulated in breast cancer (Benevides et al., 2013) and gastric adenocarcinoma (Chen et al., 2011). Upregulation of IL-17A mRNA was reported in synovial fluid from RA patients (Chen et al., 2020).

\section{Conclusion}

ZNf804a and CDk1 genes have been identified as pivotal genes in various autoimmune diseases. These genes are implicated in RA progression through their effects on the expression of various cytokines as TNF- $\alpha$ and IFN-1. 14-3-3 $\eta$ is a relatively novel biomarker for RA. Overexpression of YWHAH 14-3-3 $\eta$ gene is associated with RA. IL-17A is considered an important cytokine in RA as it is produced by several immune cells. There is an increase in IL-17A gene expression in synovial fluid from RA patients, which may contribute to synovitis. Yet, large scale studies are recommended to confirm the association of these novel genetic factors with inflammatory rheumatic diseases.

\section{Conflict of Interest}

None of the authors have any conflicts of interest.

\section{References:}

Aleem E., Kiyokawa H. and Kaldis P. 2005. Cdc2cyclin E complexes regulate the G1/S phase transition. Nat Cell Biol 7(8), 831-836.

Almlof J. C., Alexsson A., Imgenberg-Kreuz J., Sylwan L., Backlin C., Leonard D., Nordmark G., Tandre K., Eloranta M. L., Padyukov L., Bengtsson C., Jonsen A., Dahlqvist S. R., Sjowall C., Bengtsson A. A., Gunnarsson I., Svenungsson E., Ronnblom L., Sandling J. K. and Syvanen A. C. 2017. Novel risk genes for systemic lupus erythematosus predicted by random forest classification. Sci Rep 7(1), 6236.

Balakrishnan L., Bhattacharjee M., Ahmad S., Nirujogi R. S., Renuse S., Subbannayya Y., Marimuthu A., Srikanth S. M., Raju R., Dhillon M., Kaur N., Jois R., Vasudev V., Ramachandra Y., Sahasrabuddhe N. A., Prasad Ts K., Mohan S., Gowda H., Shankar S. and Pandey A. 2014. Differential proteomic analysis of synovial fluid from rheumatoid arthritis and osteoarthritis patients. Clin Proteomics 11(1), 1.

Benevides L., Cardoso C. R., Tiezzi D. G., Marana H. R., Andrade J. M. and Silva J. S. 2013. Enrichment of regulatory $\mathrm{T}$ cells in invasive breast tumor correlates with the upregulation of IL-17A expression and invasiveness of the tumor. Eur $\mathbf{J}$ Immunol 43(6), 1518-1528.

Beringer A., Noack M. and Miossec P. 2016. IL-17 in Chronic Inflammation: From Discovery to Targeting. Trends Mol Med 22(3), 230-241.

Blake J., Riddell A., Theiss S., Gonzalez A. P., Haase B., Jauch A., Janssen J. W., Ibberson D., Pavlinic D., Moog U., Benes V. and Runz H. 2014. Sequencing of a patient with balanced chromosome abnormalities and neurodevelopmental disease identifies disruption of multiple high risk loci by structural variation. PLoS One 9(3), e90894. 
Bottini N. and Firestein G. S. 2013. Duality of fibroblast-like synoviocytes in RA: passive responders and imprinted aggressors. Nat Rev Rheumatol 9(1), 24-33.

Chabaud M., Durand J. M., Buchs N., Fossiez F., Page G., Frappart L. and Miossec P. 1999. Human interleukin-17: A $\mathrm{T}$ cell-derived proinflammatory cytokine produced by the rheumatoid synovium. Arthritis Rheum 42(5), 963-970.

Chabaud M., Fossiez F., Taupin J. L. and Miossec P. 1998. Enhancing effect of IL-17 on IL-1-induced IL-6 and leukemia inhibitory factor production by rheumatoid arthritis synoviocytes and its regulation by Th2 cytokines. J Immunol 161(1), 409-414.

Chabaud M., Garnero P., Dayer J. M., Guerne P. A., Fossiez F. and Miossec P. 2000. Contribution of interleukin 17 to synovium matrix destruction in rheumatoid arthritis. Cytokine 12(7), 1092-1099.

Chen J. G., Xia J. C., Liang X. T., Pan K., Wang W., Lv L., Zhao J. J., Wang Q. J., Li Y. Q., Chen S. P., He J., Huang L. X., Ke M. L., Chen Y. B., Ma H. Q., Zeng Z. W., Zhou Z. W., Chang A. E. and Li Q. 2011. Intratumoral expression of IL-17 and its prognostic role in gastric adenocarcinoma patients. Int J Biol Sci 7(1), 53-60.

Chen S., Blijdorp I., van Mens L., Bowcutt R., Latuhihin T., van de Sande M., Shaw S., Yeremenko N. and Baeten D. 2020. IL-17A and IL$17 \mathrm{~F}$ expression and functional responses in rheumatoid arthritis and peripheral spondyloarthritis. J Rheum 190571.

Consortium W. T. C. C. 2007. Genome-wide association study of 14,000 cases of seven common diseases and 3,000 shared controls. Nature 447(7145), 661.

Cribbs A., Feldmann M. and Oppermann U. 2015. Towards an understanding of the role of DNA methylation in rheumatoid arthritis: therapeutic and diagnostic implications. Ther Adv Musculoskelet Dis 7(5), 206-219.

Crosby M. E. 2007. Cell Cycle: Principles of Control. Yale J Biol Med 80(3), 141-142. de Launay D., van de Sande M. G., de Hair M. J., Grabiec A. M., van de Sande G. P., Lehmann K. A., Wijbrandts C. A., van Baarsen L. G., Gerlag D. M., Tak P. P. and Reedquist K. A. 2012. Selective involvement of ERK and JNK mitogen-activated protein kinases in early rheumatoid arthritis (1987 ACR criteria compared to 2010 ACR/EULAR criteria): a prospective study aimed at identification of diagnostic and prognostic biomarkers as well as therapeutic targets. Ann Rheum Dis 71(3), 415423.

Dolcino M., Ottria A., Barbieri A., Patuzzo G., Tinazzi E., Argentino G., Beri R., Lunardi C. and Puccetti A. 2015. Gene Expression Profiling in Peripheral Blood Cells and Synovial Membranes of Patients with Psoriatic Arthritis. PLoS One 10(6), e0128262.

Fattah S. A., Abdel Fattah M. A., Mesbah N. M., Saleh S. M., Abo-Elmatty D. M. and Mehanna E. T. 2020. The expression of zinc finger $804 \mathrm{a}$ (ZNF804a) and cyclin-dependent kinase 1 (CDK1) genes is related to the pathogenesis of rheumatoid arthritis. Arch Physiol Biochem.

Gibson T. J., Postma J. P., Brown R. S. and Argos P. 1988. A model for the tertiary structure of the 28 residue DNA-binding motif ('zinc finger') common to many eukaryotic transcriptional regulatory proteins. Protein Eng 2(3), 209-218.

Girgenti M. J., LoTurco J. J. and Maher B. J. 2012. ZNF804a regulates expression of the schizophrenia-associated genes PRSS16, COMT, PDE4B, and DRD2. PLoS One 7(2), e32404.

Gordon R. A., Grigoriev G., Lee A., Kalliolias G. D. and Ivashkiv L. B. 2012. The interferon signature and STAT1 expression in rheumatoid arthritis synovial fluid macrophages are induced by tumor necrosis factor alpha and counter-regulated by the synovial fluid microenvironment. Arthritis Rheum 64(10), 3119-3128. 
Griswold A. J., Ma D., Cukier H. N., Nations L. D., Schmidt M. A., Chung R. H., Jaworski J. M., Salyakina D., Konidari I., Whitehead P. L., Wright H. H., Abramson R. K., Williams S. M., Menon R., Martin E. R., Haines J. L., Gilbert J. R., Cuccaro M. L. and Pericak-Vance M. A. 2012. Evaluation of copy number variations reveals novel candidate genes in autism spectrum disorder-associated pathways. Hum Mol Genet 21(15), 3513-3523.

Grover D., Verma R., Goes F. S., Mahon P. L. B., Gershon E. S., McMahon F. J., Potash J. B., Nimh Genetics Initiative Bipolar Disorder Collaborative B. D. P. G., Gershon E. S., McMahon F. J. and Potash J. B. 2009. Family-based association of YWHAH in psychotic bipolar disorder. Am J Med Genet Part B 150B(7), 977-983.

Gurczynski S. J. and Moore B. B. 2018. IL-17 in the lung: the good, the bad, and the ugly. Am J Physiol Lung Cell Mol Physiol 314(1): L6-L16.

Hot A. and Miossec P. 2011. Effects of interleukin (IL)-17A and IL-17F in human rheumatoid arthritis synoviocytes. Ann Rheum Dis 70(5), 727-732.

Hot A., Zrioual S., Lenief V. and Miossec P. 2012. IL-17 and tumour necrosis factor $\alpha$ combination induces a HIF-1 $\alpha$-dependent invasive phenotype in synoviocytes. Ann Rheum Dis 71(8), 1393-1401.

Hot A., Zrioual S., Toh M. L., Lenief V. and Miossec P. 2011. IL-17A- versus IL-17F-induced intracellular signal transduction pathways and modulation by IL-17RA and IL-17RC RNA interference in rheumatoid synoviocytes. Ann Rheum Dis 70(2), 341-348.

Hu X., Chakravarty S. D. and Ivashkiv L. B. 2008. Regulation of interferon and Toll-like receptor signaling during macrophage activation by opposing feedforward and feedback inhibition mechanisms. Immunol Rev 22641-56.

Jakubiuk-Tomaszuk A., Sobaniec W., Rusak M., Poskrobko E., Nędzi A., Olchowik B. and Galicka A. 2015. Decrease of interleukin (IL) 17A gene expression in leucocytes and in the amount of IL17A protein in CD4+ T cells in children with Down Syndrome. Pharmacol Rep 67(6), 1130-1134.

Khan D. and Ansar Ahmed S. 2015. Regulation of IL-17 in autoimmune diseases by transcription factors and microRNAs. Front Genet 6, 236.
Kilani R. T., Maksymowych W. P., Aitken A., Boire G., St-Pierre Y., Li Y. and Ghahary A. 2007. Detection of high levels of 2 specific isoforms of 14-3-3 proteins in synovial fluid from patients with joint inflammation. J Rheumatol 34(8), 1650-1657.

Kim J. S. and Jordan M. S. 2013. Diversity of IL17-producing T lymphocytes. Cell Mol Life Sci 70(13), 2271-2290.

Kleinewietfeld M., Manzel A., Titze J., Kvakan H., Yosef N., Linker R. A., Muller D. N. and Hafler D. A. 2013. Sodium chloride drives autoimmune disease by the induction of pathogenic TH17 cells. Nature 496(7446), 518-522.

Kook S. H., Jang Y. S. and Lee J. C. 2011. Involvement of JNK-AP-1 and ERK-NF-kappaB signaling in tension-stimulated expression of type I collagen and MMP-1 in human periodontal ligament fibroblasts. J Appl Physiol (1985) 111(6), 1575-1583.

Kotake S., Udagawa N., Takahashi N., Matsuzaki K., Itoh K., Ishiyama S., Saito S., Inoue K., Kamatani N., Gillespie M. T., Martin T. J. and Suda T. 1999. IL-17 in synovial fluids from patients with rheumatoid arthritis is a potent stimulator of osteoclastogenesis. J Clin Invest 103(9), 1345-1352.

Kyttaris V. C. 2012. Kinase inhibitors: a new class of antirheumatic drugs. Drug Des Devel Ther 6, 245-250.

Li G., Zhang Y., Qian Y., Zhang H., Guo S., Sunagawa M., Hisamitsu T. and Liu Y. 2013. Interleukin-17A promotes rheumatoid arthritis synoviocytes migration and invasion under hypoxia by increasing MMP2 and MMP9 expression through NF-kB/HIF-1 $\alpha$ pathway. Mol Immunol 53(3), 227-236.

Li H., Zuo J. and Tang W. 2018. Phosphodiesterase-4 Inhibitors for the Treatment of Inflammatory Diseases. Front Pharmacol 91048.

Linke K., Mace P. D., Smith C. A., Vaux D. L., Silke J. and Day C. L. 2008. Structure of the MDM2/MDMX RING domain heterodimer reveals dimerization is required for their ubiquitylation in trans. Cell Death Differ 15(5), 841-848. 
Lohka M. J., Hayes M. K. and Maller J. L. 1988. Purification of maturation-promoting factor, an intracellular regulator of early mitotic events. Proc Natl Acad Sci U S A 85(9), 3009-3013.

MacGregor A. J., Snieder H., Rigby A. S., Koskenvuo M., Kaprio J., Aho K. and Silman A. J. 2000. Characterizing the quantitative genetic contribution to rheumatoid arthritis using data from twins. Arthritis Rheum 43(1), 30-37.

Maksymowych W. P. and Marotta A. 2014. 14-33eta: a novel biomarker platform for rheumatoid arthritis. Clin Exp Rheumatol 32(5 Suppl 85), S35-39.

Maksymowych W. P., Naides S. J., Bykerk V., Siminovitch K. A., van Schaardenburg D., Boers M., Landewé R., van der Heijde D., Tak P. P., Genovese M. C., Weinblatt M. E., Keystone E. C., Zhukov O. S., Abolhosn R. W., Popov J. M., Britsemmer K., van Kuijk A. W. and Marotta A. 2014a. Serum 14-3-3 $\eta$ is a novel marker that complements current serological measurements to enhance detection of patients with rheumatoid arthritis. J Rheumatol 41(11), 2104-2113.

Maksymowych W. P., van der Heijde D., Allaart C. F., Landewe R., Boire G., Tak P. P., Gui Y., Ghahary A., Kilani R. and Marotta A. 2014b. 14-33eta is a novel mediator associated with the pathogenesis of rheumatoid arthritis and joint damage. Arthritis Res Ther 16(2), R99.

Maurice D. H., Ke H., Ahmad F., Wang Y., Chung J. and Manganiello V. C. 2014. Advances in targeting cyclic nucleotide phosphodiesterases. Nat Rev Drug Discov 13(4), 290-314.

Miossec P. and Kolls J. K. 2012. Targeting IL-17 and TH17 cells in chronic inflammation. Nat Rev Drug Discov 11(10), 763-776.

Muratake T., Hayashi S., Ichikawa T., Kumanishi T., Ichimura Y., Kuwano R., Isobe T., Wang Y., Minoshima S., Shimizu N. and Takahashi Y. 1996. Structural organization and chromosomal assignment of the human 14-3-3 eta chain gene (YWHAH). Genomics 36(1), 63-69.

Ndongo-Thiam N. and Miossec P. 2015. A cellbased bioassay for circulating bioactive IL-17: application to destruction in rheumatoid arthritis. Ann Rheum Dis 74(8), 1629-1631.
Nemtsova M. V., Zaletaev D. V., Bure I. V., Mikhaylenko D. S., Kuznetsova E. B., Alekseeva E. A., Beloukhova M. I., Deviatkin A. A., Lukashev A. N. and Zamyatnin A. A. 2019. Epigenetic Changes in the Pathogenesis of Rheumatoid Arthritis. Front Genet 10(570).

Noack M., Ndongo-Thiam N. and Miossec P. 2016. Role of podoplanin in the high interleukin-17A secretion resulting from interactions between activated lymphocytes and psoriatic skin-derived mesenchymal cells. Clin Exp Immunol 186(1), 6474.

Nurse P. and Thuriaux P. 1980. Regulatory genes controlling mitosis in the fission yeast Schizosaccharomyces pombe. Genetics 96(3), 627637.

Okada Y., Wu D., Trynka G., Raj T., Terao C., Ikari K., Kochi Y., Ohmura K., Suzuki A. and Yoshida S. 2014. Genetics of rheumatoid arthritis contributes to biology and drug discovery. Nature 506(7488), 376-381.

Petri M. 2006. Systemic lupus erythematosus: 2006 update. J Clin Rheumatol 12(1), 37-40.

Rao S., Yao Y., Ryan J., Jin C., Xu Y., Huang X., Guo J., Wen Y., Mao C., Meyre D. and Zhang F. 2017. Genetic association of rs1344706 in ZNF804A with bipolar disorder and schizophrenia susceptibility in Chinese populations. Sci Rep 741140 .

Rhodes B., Merriman M. E., Harrison A., Nissen M. J., Smith M., Stamp L., Steer S., Merriman T. R. and Vyse T. J. 2010. A genetic association study of serum acute-phase C-reactive protein levels in rheumatoid arthritis: implications for clinical interpretation. PLoS Med 7(9), e1000341e1000341.

Sekine C., Sugihara T., Miyake S., Hirai H., Yoshida M., Miyasaka N. and Kohsaka H. 2008. Successful treatment of animal models of rheumatoid arthritis with small-molecule cyclindependent kinase inhibitors. J Immunol 180(3), 1954-1961. 
Siebuhr A. S., Bay-Jensen A. C., Leeming D. J., Plat A., Byrjalsen I., Christiansen C., van de Heijde D. and Karsdal M. A. 2013. Serological identification of fast progressors of structural damage with rheumatoid arthritis. Arthritis Res Ther 15(4), R86.

Smolen J. S., Aletaha D. and McInnes I. B. 2016. Rheumatoid arthritis. Lancet 388(10055), 2023 2038.

Smolen J. S. and Steiner G. 2003. Therapeutic strategies for rheumatoid arthritis. Nat Rev Drug Discov 2(6), 473-488.

Steinberg S., Mors O., Borglum A. D., Gustafsson O., Werge T., Mortensen P. B., Andreassen O. A., Sigurdsson E., Thorgeirsson T. E., Bottcher Y., Olason P., Ophoff R. A., Cichon S., Gudjonsdottir I. H., Pietilainen O. P., Nyegaard M., TuulioHenriksson A., Ingason A., Hansen T., Athanasiu L., Suvisaari J., Lonnqvist J., Paunio T., Hartmann A., Jurgens G., Nordentoft M., Hougaard D., Norgaard-Pedersen B., Breuer R., Moller H. J., Giegling I., Glenthoj B., Rasmussen H. B., Mattheisen M., Bitter I., Rethelyi J. M., Sigmundsson T., Fossdal R., Thorsteinsdottir U., Ruggeri M., Tosato S., Strengman E., Kiemeney L. A., Melle I., Djurovic S., Abramova L., Kaleda V., Walshe M., Bramon E., Vassos E., Li T., Fraser G., Walker N., Toulopoulou T., Yoon J., Freimer N. B., Cantor R. M., Murray R., Kong A., Golimbet V., Jonsson E. G., Terenius L., Agartz I., Petursson H., Nothen M. M., Rietschel M., Peltonen L., Rujescu D., Collier D. A., Stefansson H., St Clair D. and Stefansson K. 2011. Expanding the range of ZNF804A variants conferring risk of psychosis. Mol Psychiatry 16(1), 59-66.

TakahashiY. 2003. The 14-3-3 proteins: gene, gene expression, and function. Neurochem Res 28(8), 1265-1273.

Talkowski M. E., Rosenfeld J. A., Blumenthal I., Pillalamarri V., Chiang C., Heilbut A., Ernst C., Hanscom C., Rossin E., Lindgren A. M., Pereira S., Ruderfer D., Kirby A., Ripke S., Harris D. J., Lee J. H., Ha K., Kim H. G., Solomon B. D., Gropman A. L., Lucente D., Sims K., Ohsumi T. K., Borowsky M. L., Loranger S., Quade B., Lage K., Miles J., Wu B. L., Shen Y., Neale B., Shaffer L. G., Daly M. J., Morton C. C. and Gusella J. F. 2012. Sequencing chromosomal abnormalities reveals neurodevelopmental loci that confer risk across diagnostic boundaries.. Cell 149(3), 525-537.

Vrana K. E., Churchill M. E., Tullius T. D. and Brown D. D. 1988. Mapping functional regions of transcription factor TFIIIA. Mol Cell Biol 8(4), 1684-1696.

Walters J. T., Corvin A., Owen M. J., Williams H., Dragovic M., Quinn E. M., Judge R., Smith D. J., Norton N., Giegling I., Hartmann A. M., Moller H. J., Muglia P., Moskvina V., Dwyer S., O'Donoghue T., Morar B., Cooper M., Chandler D., Jablensky A., Gill M., Kaladjieva L., Morris D. W., O'Donovan M. C., Rujescu D. and Donohoe G. 2010. Psychosis susceptibility gene ZNF804A and cognitive performance in schizophrenia. Arch Gen Psychiatry 67(7), 692-700.

Wang H. S., Duan S. W., Xing Q. H., Du J., Li X. W., Xu Y. F., Zhang Z. Z., Wang Y. J., Feng G. Y. and He L. 2005. [Association study between NPY and YWHAH gene polymorphisms and schizophrenia]. Yi Chuan Xue Bao 32(12), 12351240.

Wei S. T., Sun Y. H., Zong S. H. and Xiang Y. B. 2015. Serum Levels of IL-6 and TNF-alpha May Correlate with Activity and Severity of Rheumatoid Arthritis. Med Sci Monit 2140304038 .

Wu L., Qin Y., Xia S., Dai M., Han X., Wu Y., Zhang X., Ma J., Wang Y., Tang Y., Liu Z., Zhu W., Jallal B., Yao Y., Qu B. and Shen N. 2016. Identification of Cyclin-Dependent Kinase 1 as a Novel Regulator of Type I Interferon Signaling in Systemic Lupus Erythematosus. Arthritis Rheumatol 68(5), 1222-1232.

Zrioual S., Toh M. L., Tournadre A., Zhou Y., Cazalis M. A., Pachot A., Miossec V. and Miossec P. 2008. IL-17RA and IL-17RC receptors are essential for IL-17A-induced ELR+ CXC chemokine expression in synoviocytes and are overexpressed in rheumatoid blood. J Immunol 180(1), 655-663. 